\title{
The Effect of Heparin on In Vitro Stimulated Platelet Aggregation by Elective Percutaneous Coronary Intervention
}

\section{Ebru İpek Türkoğlu, Nazan Bitir}

İzmir Kemalpaşa State Hospital, Clinic of Cardiology, İzmir, Turkey

\begin{abstract}
Background: The aim of the present study was to investigate the effects of heparin on in vitro stimulated platelet aggregation by elective percutaneous coronary intervention

Methods: Thirty elective percutaneous coronary angioplasty (PTCA) patients were included in the present study. The patients were administered heparin as anticoagulant agent during PTCA. Two blood samples were obtained during the intervention before and 10 minutes after heparin bolus and stimulated platelet aggregation responses were investigated.
\end{abstract}

Results: The difference in platelet aggregation response to adenosine diphosphate (ADP) before and after unfractionated heparin (UFH) was statistically significant $(p<0.05)$. The differences in platelet aggregation responses to collagen, to epinephrine, and to ristocetin before and after UFH were not statistically significant $(\mathrm{p}>0.05)$.

Conclusion: Heparin increases in vitro platelet aggregation stimulated with ADP in elective PTCA patients. This finding might explain the prothrombotic tendency of heparin, however further investigations are needed.

Keywords: Heparin, stimulated platelet aggregation, elective PTCA

The original research "The effect of heparin on in vitro stimulated platelet aggregation by elective percutaneous coronary intervention" has been accepted and has been presented as oral presentation both in the Cuban Congress of Cardiology has been held in June 2014 and in $\mathbf{1 0}^{\text {th }}$ International Congress of Update in Cardiology and Cardiovascular Surgery (Antalya, Turkey, March 13-26, 2014) and published in the Supplement to the American Journal of Cardiology as an abstract.

Türkoğlu Eİ., Bitir N. The Effect of Heparin on In Vitro Stimulated Platelet Aggregation by Elective Percutaneous Coronary Intervention. EJCM 2018;06(4):140-144. DOI: 10.32596/ejcm.00049

Address for Correspondence: Ebru İpek Türkoğlu, İzmir Kemalpaşa State Hospital, Clinic of Cardiology, İzmir, Turkey

e-mail: dripek73@yahoo.com

Received: 07.09.2018 Accepted: 29.11.2018 Published: 30.11.2018

${ }^{\circ}$ Copyright 2018 by Heart and Health Foundation of Turkey (TÜSAV) / E Journal of Cardiovascular Medicine published by Galenos Publishing House. 


\section{Introduction}

Heparin is widely used in cardiology practice both for treatment and prevention of thromboembolic diseases. (1) Especially in acute coronary syndromes and coronary interventional procedures, unfractionated heparin (UFH) is the standard anticoagulant agent. ${ }^{(1)}$ Although the number and the outcomes of percutaneous coronary interventions (PCI) have improved because of innovations in techniques, materials as stents and new antiaggregant agents over years, the clot formation in coronary arteries remains still as an important issue. However, some unfavorable effects of heparin are also known in addition to its anticoagulant properties. ${ }^{(2)}$ There are many reports that heparin can modify platelet functions both in vitro and in vivo, bind extensively to platelets and its high doses (30-70U/mL) induce spontaneously platelet aggregation in vitro. ${ }^{(1,3-5)}$ The anticoagulant effect of heparin is based on its activity to bind antithrombin-3 (AT-3) and compose a heparin-AT-3 complex. ${ }^{(6)}$ Furthermore, heparin blocks the thrombin action on platelets but some other activities of platelets continue despite heparin. The heparin-AT-3 complex formation protects platelets from aggregation. ${ }^{(2)}$ Platelet reactivity can be measured by the platelet response to some agonists.

There are several studies investigated the effect of UFH on platelet aggregation response using several methods to certain physiological agonists and reports are controversial. ${ }^{(1-3,5,7,8)}$ The aim of the present study was to investigate the effect of UFH on in vitro stimulated platelet aggregation by using $\%$ aggregation test to certain agonists in elective PCI patients and the clinical significance of aggregation response to UFH.

\section{Materials and Methods}

\section{Study Population}

The study included 30 patients older than 30 years with stable angina pectoris and documented ischemia (positive treadmill exercise test or positive myocardial perfusion scan for ischemia), who underwent coronary angiography and scheduled for elective PCI. Exclusion criteria were: 1) unstable state or acute coronary syndrome, 2) stable angina with an identified precipitating factor (e.g. severe anemia, heart failure, tachyarrhythmia, thyrotoxicosis, severe uncontrolled hypertension), 3) myocardial infarction or PCI in previous month or coronary bypass surgery in 2 months, 4) treatment with UFH or low molecular weight heparin $>24$ hours of any cause before enrollment, 5) treatment with any other anti-platelet agent than aspirin (e.g. clopidogrel, ticlopidin, dipridamol), 6) refusal of patient. All patients are followed up for 30 days.

\section{Blood Collection}

Immediately after femoral arterial sheath replacement the first blood sample was taken from a peripheral vein to determine basal (before anticoagulant) platelet aggregation response. Heparin is given $100 \mathrm{U} / \mathrm{kg}$ (not exceeding maximum dose of 10000 units) intravenous bolus after the percutaneous coronary angioplasty-wire crossed the lesion. Dose adjustment was made to achieve 1.5-2.5 times of basal activated clotting time. Ten minutes after the administration of heparin the second blood sample was taken also from a peripheral vein. After successful stent implantation, a loading dose of clopidogrel $600 \mathrm{mg}$ was given to the patients in the catheter laboratory.

\section{In Vitro Platelet Aggregation Measurement}

Immediately after blood collection, platelet aggregation measurements are made. All blood samples are studied into 2 hours after their collection. In vitro platelet functions were evaluated in the hematology laboratory with aggregometer. Stimuli were adenosine diphosphate (ADP), collagen, epinephrine and ristocetin. PAP-4CD Bio-Data was used for platelet aggregation.

All procedures performed in studies involving human participants were in accordance with the ethical standards of the institutional research committee and with the 1964 Helsinki Declaration and its later amendments or comparable ethical standards.

The study was approved by the institutional review committee and informed consent was obtained from all individual participants included in the study. 


\section{Statistical Analysis}

Continuous parametric and non-parametric data are presented as mean \pm standard deviation. A student-paired t-test was applied to assess the differences between preand post-heparin platelet aggregation responses. The level of significance was set at $\mathrm{p}<0.05$. The Statistical Package for Social Science (SPSS Inc., version 15.0 for Windows) was used for statistical analyses.

\section{Results}

Baseline clinical characteristics of study population and concomitant medications were described in Tables 1 and 2. Thirty patients (male: $n=21,70 \%$ vs female: $n=9$, $30 \%$ ), included in the study. Mean age was $55.7 \pm 2.5$ years. Eighteen patients $(60 \%)$ were smoker. Only 6 patients $(20 \%)$ had diabetes mellitus and none were on insulin treatment. Twenty patients (66.6\%) had hypertension and were under treatment. Twenty-four patients $(80 \%)$ were under statin treatment since their coronary angiography procedures.

Study patients (100\%) had been receiving aspirin $100 \mathrm{mg}$ per day more than 7 days before the procedure.

Table 1. Baseline characteristics of the patients

\begin{tabular}{|l|l|}
\hline Characteristic & n (\%) \\
\hline Age (years) & $55.7 \pm 2.5$ \\
\hline Gender & $21(70 \%)$ \\
\hline Male & $9(30 \%)$ \\
\hline Female & $18(60 \%)$ \\
\hline Smoker & $6(20 \%)$ \\
\hline Diabetes mellitus & $20(66.6 \%)$ \\
\hline Hypertension & $24(80 \%)$ \\
\hline Hyperlidemia &
\end{tabular}

Table 2. Concomitant medications of the study patients

\begin{tabular}{l|l|} 
Medication & $\mathbf{n ~ ( \% )}$ \\
\hline ASA $>$ 7 days & $30(100 \%)$ \\
\hline B-blocker & $26(86.6 \%)$ \\
\hline Nitrate & $18(60 \%)$ \\
\hline ACE-1 & $20(66.6 \%)$ \\
\hline Statin & $24(80 \%)$ \\
\hline
\end{tabular}

ACE: Angiotensin-converting enzyme
All of patients have received a $600 \mathrm{mg}$ loading dose of clopidogrel after successful stent implantation in the catheter laboratory as part of dual antiplatelet theraphy. Twenty-six patients $(86.6 \%)$ were taking beta-blockers. Twenty patients $(66.6 \%)$ were using nitrates. All of the hypertensive patients $(n=20,66.6 \%)$ were taking angiotensin-converting enzyme-inhibitors and all patients with a low-density lipoprotein level $>70 \mathrm{mg} / \mathrm{dL}$ were taking statins.

Baseline platelet counts were within the normal limits in all patients. After the intravenous administration of UFH, platelet counts were remained unchanged $\left(214 \pm 47 \times 10^{6} \mathrm{per}\right.$ $1 \mathrm{~mL}$ before UFH and $210 \pm 34 \times 10^{6}$ per $1 \mathrm{~mL}$ after UFH). Not any major bleeding complications did occur. Only 5 of patients had small hematoma on the femoral access site. In-hospital ischemic or infectious complications were not experienced.

Stimulated platelet aggregation responses before and after UFH were summarized in Table 3. Values were given as mean \pm standard error of $\%$ aggregation. Platelet aggregation responses to ADP were $36.3 \pm 4.1$ before UFH and $40.9 \pm 4.2$ after UFH, and the difference was statistically significant $(\mathrm{p}=0.01)$. Platelet aggregation responses to collagen were $50.2 \pm 4.5$ before UFH and $48.5 \pm 4.3$ after UFH; to epinephrine $33.7 \pm 3.5$ before UFH and $34.1 \pm 3.9$ after $U F H$; to ristocetin $76.2 \pm 2.4$ before UFH and $70.1 \pm 4.0$ after UFH, and all showed no statistically significant effect.

\section{Discussion}

In recent years there have been lots of innovations in interventional cardiology such as new stents, new drugs

Table 3. Stimulated platelet aggregation responses

\begin{tabular}{|l|l|l|l|}
\hline Stimuli & $\begin{array}{l}\text { Before UFH } \\
(\mathbf{n = 3 0 )}\end{array}$ & $\begin{array}{l}\text { After UFH } \\
(\mathbf{n = 3 0 )}\end{array}$ & $\mathbf{p}$ value \\
\hline ADP & $36.3 \pm 4.1$ & $40.9 \pm 4.2$ & $\mathbf{0 . 0 1}$ \\
\hline Collagen & $50.2 \pm 4.5$ & $48.5 \pm 4.3$ & 0.19 \\
\hline Epinephrine & $33.7 \pm 3.5$ & $34.1 \pm 3.9$ & 0.84 \\
\hline Ristocetin & $76.2 \pm 2.4$ & $70.1 \pm 4.0$ & 0.13 \\
\hline
\end{tabular}

ADP: Adenosine diphosphate, UFH: Unfractionated heparin 
and new techniques, but clot formation in coronary arteries remains still as an important issue. More than 30 years the UFH has been the primary anticoagulant agent for PCI, but the optimal dosage and the monitoring of anticoagulation level (e.g. poor correlations between activated clotting time and activated partial thromboplastin time) remain controversial(1). Also, itmay introduce some unpredictable anticoagulative response and platelet activation. ${ }^{(4,5)}$ This present study showed that UFH significantly increases $\%$ platelet aggregation to ADP, however UFH does not affect the aggregation responses to other agonists such as collagen, epinephrine and ristocetin.

In unstable patients such as acute coronary syndrome or myocardial infarction, once the platelet aggregation has been already initiated, the platelet aggregation responses to UFH may differ because of the activated aggregation and coagulation cascade. All unstable patients were excluded to avoid this kind of interactions. The aim of the present study was to investigate the aggregation response of stable patients to UFH via platelet functions beyond its anticoagulation activity. In the present study, no significant effect of UFH was observed on platelet aggregation responses stimulated with collagen, epinephrine and ristocetin, but UFH significantly increased platelet aggregation to ADP in elective PCI patients, which was consistent with some former study results..$^{(1-3,5,7)}$ Although a significant increase in platelet aggregation response to ADP was observed in the present study, none of the patients experienced any ischemic complications such as acute or subacute stent thrombosis or ischemic cerebrovascular complication neither in 72 hours nor in 30 days in follow up. This finding let us question the clinical meaning of this proaggregant effect shown in the laboratory tests, which may be related to our small number of patients.

In vitro heparin has been reported to reduce, enhance or have no effect on platelet aggregation, depending on the type of aggregation tests and because of the heterogeneous mixture of heparin molecule. ${ }^{(1,3,5,8)}$ The anticoagulant effect of heparin results from its ability to bind and activate AT-3. ${ }^{(3)}$ Heparin blocks the effect of thrombin on platelets, but many other activities of platelets proceed despite heparin. ${ }^{(3,9)}$ The interactions between heparin and platelets are complex and not completely understood. Heparin binds platelet surface and modifies responsiveness. ${ }^{(4-6,10,11)}$ When UFH is administered intravenous rapidly it may reduce platelet counts and prolong bleeding times. ${ }^{(12,13)}$ In vitro, high doses of heparin are likely to increase platelet aggregation and low doses are more have a tendency to reduce it, ${ }^{(7,13)}$ which suggests properly heparin dosing is very important. The proaggregant response of UFH is detected with some physiological agonists. It is more consistently seen with low concentrations of ADP and less consistently with higher concentrations. ${ }^{(3,8,13)}$ These findings suggest that the proaggregant effect of UFH is moderate and can be overcome with strong platelet stimulation. ${ }^{(13)}$ These findings could also give an explanation why this effect was detected only at supratherapeutic concentrations of heparin in most studies that make the dosage monitoring a significant issue.

Heparin molecule has two types of binding sites. ${ }^{(3)}$ One site binds either to AT-3 or to platelets but has a higher affinity for AT-3 and the second site binds preferentially to platelets. ${ }^{(3)}$ The interaction between heparin and platelets is markedly increased on activated platelets. ${ }^{(9)}$ Heparin inhibits all platelet activities induced by thrombin, including aggregation, when AT-3 is present. ${ }^{(7)}$ The indirect effect of heparin to inhibit thrombin-induced platelet aggregation, require a cofactor, AT-3. ${ }^{(2)}$ The heparin-AT-3 complex has limited effects on thrombin bound to fibrin, ${ }^{(14)}$ so heparin may stimulate platelets within or in the region of the blood clot and paradoxically support local thrombogenic stimulation. ${ }^{(2)}$ Circulating thrombin is inactivated by AT3 , but fibrin bound thrombin is relatively inaccessible to inhibit by heparin-AT-3 complex. So platelet activation may become significant at the thrombus site especially in unstable patients, even weak systematically and counteracted by the anticoagulant effect. ${ }^{(2)}$ Because unstable angina can be associated with elevated levels of platelet factor 4 and thromboglobulin, ${ }^{(15,16)}$ increased 
thromboxane A2 and thrombin generation, ${ }^{(17,18)}$ only stable patients were enrolled.

\section{Limitations}

The limitations of the present study were small number of patients and lack of unstable patients. In acute coronary syndromes and unstable patients, especially by the site of thrombus, the proaggregant effect of heparin may be more critical, but further studies are needed.

\section{Conclusions}

UFH may enhance platelet aggregation in elective PCI patients treated with acetylsalicylic acid only. With the knowledge of the stronger the platelet inhibition, the lower the incidence of ischemic complications, ${ }^{(19-22)}$ choice of the anticoagulant agent or additional antiaggregant agents before PCI may be beneficial.

Acknowledgements: We are thankfull to Eser Şekercioğlu, PhD (Dataist Analytics, Ireland) for his great effort on statistical analysis.

Disclosure and conflicts of interest: The authors declare no conflict of interest.

\section{References}

1. Mascelli MA, Kleiman NS, Marciniak SJ Jr, Damaraju L, Weisman HF, Jordan RE. Therapeutic heparin concentrations augment platelet reactivity: Implications for the pharmacologic assessment of the glycoprotein IIb/IIIa antagonist abciximab. Am Heart J 2000;139:696-703.

2. Xaio Z, Theroux P. Platelet activation with unfractionated heparin at therapeutic concentrations and comparison with a low-molecular-weight heparin and with a direct thrombin inhibitor. Circulation 1998;97:251-6.

3. Salzman EW, Rosenberg RD, Smith MH, Lindon JN, Favreau L. Effect of heparin and heparin fractions on platelet aggregation. J Clin Invest 1980;65:64-73.

4. Eika C. Inhibition of thrombin-induced aggregation of human platelets in heparin. Scand J Haematol 1971;8:216-22.

5. Thomson C, Forbes CD, Prentice CR. The potentiation of platelet aggregation and adhesion by heparin in vitro and in vivo. Clin Sci Mol Med 1973;45:48594.

6. Rosenberg RD. Actions and interactions of antithrombin and heparin. N Engl J Med 1975;292:146-51.

7. Eika C. On the mechanism of platelet aggregation induced by heparin, protamine, and polybrene. Scand J Haematol 1972;9:248-57.
8. Eika C. The platelet aggregation effect of eight commercial heparins. Scand J Haematol 1972;9:480-2.

9: Horne MK. Heparin binding to normal and abnormal platelets. Thromb Res 1988;51:135-44

10. Goldstad GO, Solumn NO, Krutnes MB. Heparin binding platelet proteins demonstrated by crossed affinity immunoelectrophoresis. Br J Haematol 1983;53:563-6.

11. Sobel M, Adelman B. Characterization of platelet binding of heparins and other glycosaminoglycans. Thromb Res 1988;50:815-26.

12. Holmer E, Lindhal U, Backström G, et al. Anticoagulant activities and effects on platelet of a heparin fragment with high affinity for antithrombin. Thromb Res 1980;18:861-9.

13.Westwick J, Scully MF, Poll C, Kakkar VV. Comparison of low molecular weight heparin and unfractionated heparin on activation of human platelets in vitro. Thromb Res 1986;42:435-47

14. Weitz JI, Hudoba M, Massel D, Maraganore J, Hirsh J. Clot-bound thrombin is protected from inhibition by heparin-antithrombin but is susceptible to inactivation by antithrombin III-independent inhibitors. J Clin Invest 1990;86:385-91

15. Melina G, Colivicchi F, Bevilacqua E, Mangnanimi S, Melina D. Blood pressure variations, haemorheological determinants, and platelet aggregation in hypertensive patients eith unstable angina. Clin Exp Hypertens 1995;17:1145-56.

16. al-Nozha M, Gader AM, al-Momen AK, Noah MS, Jawaid M, Arafa M. Haemostatic variables in patients with unstable angina. Int $\mathrm{J}$ Cardiol 1994;43:268-77.

17. Fitzgerald DJ, Roy L, Catella F, FitzGerald GA. Platelet activation in unstable coronary disease. N Engl J Med 1986;315:983-9.

18. Théroux P, Latour JG, Léger-Gauthier C, De Lara J. Fibrinopeptide A and platelet factor levels in unstable angina pectoris. Circulation 1987;75:15662 .

19. Mehta SR, Yusuf S, Peters RJ, et al. Effects of pretreatment with clopidogrel and aspirin followed by long-term therapy in patients undergoing percutaneous coronary intervention: the PCI-CURE study. Lancet 2001;358:527-33.

20. Patti G, Colonna G, Pasceri V, Pepe LL, Montinaro A, Di Sciascio G. Randomized trial of high loading dose of clopidogrelfor reduction of periprocedural myocardial infarction in patients undergoing coronary intervention: results from the ARMYDA-2 study. Circulation 2005;111:2099-106

21. Wiviott SD, Braunwald E, McCabe CH, et al. Prasugrel versus clopidogrel in patients with acute coronary syndromes. N Engl J Med 2007;357:200115 .

22. Wallentin L, Becker RC, Budaj A, et al. Ticagrelor versus clopidogrel in patients with acute coronary syndromes. N Eng J Med 2009;361:1045-57. 